\title{
PENGARUH PENAMBAHAN AKTIVATOR DALAM PEMBUATAN KARBON AKTIF AMPAS TAHU SEBAGAI ADSORBEN MINYAK JELANTAH
}

\section{[Effect of the Addition of Activator in the Production of Activated Carbon of Soybean Curd Residue as Used Cooking Oil Adsorbent]}

\author{
Ma'rifah $^{1^{\star}}$, Jamaluddin $^{1}$, Yonelian Yuyun${ }^{1}$, Agustinus Widodo ${ }^{1}$ \\ 1) Jurusan Farmasi, Fakultas MIPA, Universitas Tadulako \\ J. Soekarno-Hatta km 9, Palu, Sulawesi Tengah \\ *)Corresponding Author : marifahsupriadi@yahoo.co.id (hp: 081340028919)
}

Diterima 30 Desember 2017, Disetujui 10 April 2018

\begin{abstract}
The cooking oil that is repeatedly used will be damaged and cause the increase of peroxide value and free fatty acids, which are harmful to health. This research varied the activators on the activated carbon's making process in soybean curd that are $\mathrm{NaCl} 10 \%, \mathrm{Na}_{2} \mathrm{CO}_{3} 5 \%$ and $\mathrm{H}_{3} \mathrm{PO}_{4} 1 \mathrm{M}$, to know its effect to the free fatty acid content and peroxide numbers in used cooking oil. The used oil was the packaged cooking oil to fry dried fishes, fresh fishes, Tempe-tofu and chickens. Oil purification steps were despising, neutralization, and bleaching. The examination referred to SNI (Indonesian National Standard) 7709:2012 as the requirement of cooking oil quality. The result showed the highest and the lowest of free fatty acid content of $0.1925 \%$ and $0.1473 \%$, while the stiffest and the meanest the peroxide value are $9.302 \mathrm{meq}_{2} / \mathrm{kg}$ and $4.3256 \mathrm{meq} \mathrm{O}_{2} / \mathrm{kg}$. The most affecting activator in Decrease of free fatty acid and peroxide value is $\mathrm{Na}_{2} \mathrm{CO}_{3}$ were obtained from the average content of the free fatty acid $0.1473 \%$ with decrease percentage are $57,68 \%$, and the average of the decrease of peroxide value are 4,3526 meq O2/kg by the decrease percentage is $59,04 \%$. The result suggest that $\mathrm{Na}_{2} \mathrm{CO}_{3}$ is the best activator to activated the soybean curd residue as used cooking oil adsorbent.
\end{abstract}

Keywords: Activator, Activated Carbon, Soybean Curd Residue, Adsorbent, Used Cooking Oil.

\begin{abstract}
ABSTRAK
Minyak goreng yang telah digunakan berulang kali akan mengalami kerusakan seperti peningkatan bilangan peroksida dan asam lemak bebas yang dapat menimbulkan bahaya bagi kesehatan. Penelitian ini memvariasikan aktivator pada proses pembuatan karbon aktif ampas tahu yaitu $\mathrm{NaCl}$ $10 \%, \mathrm{Na}_{2} \mathrm{CO}_{3} 5 \%$ dan $\mathrm{H}_{3} \mathrm{PO}_{4} 1 \mathrm{M}$ untuk mengetahui pengaruhnya terhadap kadar asam lemak bebas dan bilangan peroksida dalam minyak jelantah. Minyak yang digunakan adalah minyak goreng kemasan yang digunakan untuk menggoreng ikan kering, ikan basah, tahu-tempe dan daging ayam. Tahapan pemurnian minyak yaitu proses despising, netralisasi dan bleaching. Pengujian mengacu pada SNI (Standar Nasional Indonesia) 7709:2012 sebagai syarat mutu minyak goreng. Hasil penelitian menunjukkan kadar asam lemak bebas tertinggi dan terendah yang diperoleh yaitu $0,1925 \%$ dan $0,1473 \%$, sedangkan bilangan peroksida tertinggi dan terendah yaitu 9,3203 meq $\mathrm{O}_{2} / \mathrm{kg}$ dan 4,3526 meq $\mathrm{O}_{2} / \mathrm{kg}$. Aktivator yang paling berpengaruh pada penurunan kadar asam lemak bebas dan bilangan peroksida adalah $\mathrm{Na}_{2} \mathrm{CO}_{3}$ dimana diperoleh kadar rata - rata asam lemak bebas $0,1473 \%$ dengan persentase penurunan sebesar $57,68 \%$ dan kadar rata - rata penurunan bilangan peroksida yaitu $4,3526 \mathrm{meq}_{2} / \mathrm{kg}$ dengan persentase penurunan sebesar $59,04 \%$. Jadi, aktivator $\mathrm{Na}_{2} \mathrm{CO}_{3}$ merupakan aktivator yang paling baik digunakan untuk aktivasi karbon ampas tahu sebagai adsorben minyak jelantah.
\end{abstract}

Kata Kunci: Aktivator, Karbon Aktif, Ampas Tahu, Adsorben, Minyak Jelantah. 


\section{LATAR BELAKANG}

Minyak goreng merupakan produk pangan yang digunakan untuk mengolah makanan. Penggunaan minyak goreng berkaitan erat dengan kesehatan, yang mana jika digunakan berulang kali dapat menimbulkan bahaya bagi kesehatan. Pemakaian minyak goreng berulang kali menyebabkan perubahan karena proses pemanasan yang dapat menyebakan terjadinya oksidasi, sehingga tingkat kerusakannya semakin tinggi. Nasir (2014) mengemukakan bahwa selain minyak menjadi kotor akibat sisa penggorengan, kerusakan juga dapat meliputi muncul aroma tengik, peningkatan asam lemak bebas, angka peroksida dan viskositas, serta terbentuknya busa (Nasir, 2014).

Penelitian yang dilakukan oleh Fadlia (2016) menunjukkan bahwa penggorengan menggunakan minyak goreng yang sama secara berulang hingga penggorengan ke-7 meningkatkan kadar asam lemak bebas dari 0,0608\% menjadi $0,5038 \%$ dan angka peroksida meningkat dari $1,7533 \mathrm{meq} / \mathrm{kg}$ menjadi $12,5492 \mathrm{meq} / \mathrm{kg}$.

Pemurnian minyak goreng bekas dapat dilakukan dengan menggunakan metode adsorbsi. Pemurnian minyak dilakukan untuk meningkatkan kualitas minyak sehingga layak untuk dikonsumsi dan mengurangi dampak yang ditimbulkan bagi kesehatan. Penggunaan adsorben dari buah mengkudu pada konsentrasi $15 \%$ dapat menurunkan kadar asam lemak bebas dari $0,6 \%$ menjadi $0,2 \%$, bilangan peroksida dari $30 \mathrm{meq} \mathrm{O}_{2} / \mathrm{kg}$ menjadi 2 meq $_{2} / \mathrm{kg}$ (Barau, 2014).

Ampas tahu merupakan limbah dari pembuatan tahu yang dapat mencemari lingkungan, namun ampas tahu dapat dimanfaatkan sebagai adsorben. Menurut Shimofuruya et al. (2011), ampas tahu merupakan adsorben yang cepat dan efektif terhadap methyl orange hingga kemampuan adsorpsi 85\%.

Ampas tahu cukup efektif dalam mengadsorpsi limbah, namun waktu kontak yang diperlukan cukup tinggi. Salah satu cara yang dapat dilakukan untuk mengatasi hal tersebut yaitu dengan menjadikan ampas tahu sebagai karbon aktif teraktivasi. Aktivasi dilakukan untuk membuka pori-pori dengan memanfaatkan senyawa kimia berupa asam ataupun garamnya sehingga kapasitas adsorpsinya menjadi lebih tinggi. Hartini et al. (2014) mengaktivasi karbon aktif ampas tahu menggunakan $\mathrm{NaCl} 10 \%$ dan menghasilkan luas permukaan pori-pori yang lebih besar yaitu 18,936 $\mathrm{m}^{2} / \mathrm{g}$. Penelitian ini bertujuan untuk mengetahui pengaruh jenis aktivator pada karbon aktif ampas tahu terhadap kadar asam lemak bebas dan bilangan peroksida pada minyak jelantah.

\section{BAHAN DAN METODE}

\section{Bahan dan Peralatan}

Bahan-bahan yang digunakan pada penelitian yaitu ampas tahu, minyak goreng baru, minyak jelantah 
penggorengan ayam, tahu-tempe, ikan basah dan ikan kering, $\mathrm{Na}_{2} \mathrm{CO}_{3} 5 \%$, $\mathrm{H}_{3} \mathrm{PO}_{4} 1 \mathrm{M}, \mathrm{NaCl} 10 \%$, aquadest, alkohol

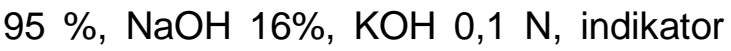
fenolftalein, $\mathrm{CH}_{3} \mathrm{COOH}, \mathrm{CHCl}_{3}$, larutan $\mathrm{KI}$ jenuh, $\mathrm{Na}_{2} \mathrm{~S}_{2} \mathrm{O}_{3} 0,1 \mathrm{~N}$, larutan pati $1 \%$, kertas saring, dan aluminium foil.

Peralatan yang digunakan yaitu gelas kimia (Iwaki Pyrex ${ }^{\circledR}$ ), lumpang dan alu, ayakan (100 mesh), corong, gelas ukur, statif dan klem, buret (Iwaki Pyrex ${ }^{\circledR}$ ), pipet tetes, erlenmeyer $\left(P_{y r e x}{ }^{\Theta}\right)$, neraca analitik (Citizen), hotplate stirer (Denville Scientific INC), termometer, oven $\left(S L{ }^{\circledR} E I\right.$ $L a b)$, cawan porselin, $\mathrm{pH}$ meter, corong pisah, desikator, tanur (LabTech).

\section{METODE PENELITIAN}

\section{Penyiapan Minyak Jelantah}

Minyak goreng yang digunakan adalah minyak jelantah yang diperoleh dari penggunaan sendiri yang telah digunakan untuk menggoreng daging ayam (DA) selama beberapa kali pengulangan menggunakan minyak goreng yang sama, temperatur yang sama, dan lama penggorengan yang sama. Pengujian kadar asam lemak bebas dan bilangan peroksida dilakukan setiap kali selesai proses penggorengan. Proses ini dilakukan hingga minyak goreng mengalami kerusakan pada tingkat yang tidak memenuhi standar minyak goreng. Prosedur tersebut diulangi untuk perlakuan tahu-tempe (TT), ikan basah (IB), dan ikan kering (IK).

\section{Preparasi Ampas Tahu (Hartini et al., 2014)}

Ampas tahu basah ditimbang sebanyak $1 \mathrm{~kg}$ kemudian dikeringkan di bawah sinar matahari selama 7 hari. Ampas tahu yang sudah dikeringkan pada sinar matahari dimasukkan dalam oven pada suhu $105^{\circ} \mathrm{C}$. Setelah itu, ampas tahu kering dihaluskan.

\section{Pembuatan Karbon Aktif Ampas Tahu}

1. Karbonisasi (Hartini et al., 2014)

Ampas tahu yang sudah dikeringkan dikarbonasi dalam tanur pada temperatur $500^{\circ} \mathrm{C}$ selama 1 jam agar menjadi karbon.

2. Aktivasi Kimia Pada Ampas Tahu

Karbon dari ampas tahu direndam dalam larutan $\mathrm{NaCl} 10 \%$, $\mathrm{Na}_{2} \mathrm{CO}_{3} 5 \%$ dan $\mathrm{H}_{3} \mathrm{PO}_{4} 1 \mathrm{M}$ masingmasing sebanyak $2 \mathrm{~g}$, dengan ratio 1:4 $(\mathrm{g} / \mathrm{mL})$ selama 5 jam sambil diaduk dengan menggunakan shaker pada suhu $45^{\circ} \mathrm{C}$, kemudian disaring dan dicuci dengan aquadest hingga $\mathrm{pH} 7$. Sampel dikeringkan dalam oven pada suhu $105^{\circ} \mathrm{C}$ sampai kering.

\section{Pemurnian Minyak Jelantah}

1. Proses Despicing (Wiyaningsih, 2010) Ditimbang sebanyak 500 gram minyak goreng bekas kemudian ditambahkan air dengan komposisi minyak : air (1:1), masukkan ke dalam gelas kimia $1000 \mathrm{~mL}$. Selanjutnya dipanaskan sampai air dalam gelas kimia tinggal setengahnya. Diendapkan dalam corong pisah 
selama 1 jam, kemudian fraksi air pada bagian bawah dipisahkan sehingga diperoleh fraksi minyak, setelah itu dilakukan penyaringan dengan kertas saring untuk memisahkan kotoran yang tersisa.

2. Proses Netralisasi (Wiyaningsih, 2010) Minyak hasil despicing sebanyak 300 gram dipanaskan sampai temperatur $35^{\circ} \mathrm{C}$, kemudian ditambahkan $12 \mathrm{~mL}$ larutan $\mathrm{NaOH}$ $16 \%$, diaduk campuran selama 10 menit pada temperatur $40^{\circ} \mathrm{C}$, selanjutnya didinginkan sampai terbentuk sabun, kemudian disaring menggunakan kertas saring.

3. Proses Bleaching (Wiyaningsih, 2010) Minyak goreng hasil netralisasi sebanyak 200 gram dipanaskan sampai suhu $70^{\circ} \mathrm{C}$, dimasukan serbuk karbon aktif ampas tahu $0,1-0,2 \%$ dari berat minyak, kemudian ditingkatkan suhunya $100^{\circ} \mathrm{C}$ pada 5 menit petama dan dilakukan pengadukan dengan hotplate stirer selama 60 menit. Selanjutnya disaring dengan kertas saring.

\section{Parameter Penelitian}

1. Bilangan Peroksida (Rohman dan Sumantri, 2007)

Sebanyak 5 gram sampel minyak ditimbang dan dimasukkan dalam erlenmeyer $250 \mathrm{~mL}$ dan ditambah $30 \mathrm{~mL}$ larutan asam asetatkloroform (3:2). Larutan digoyangkan sampai bahan terlarut semua lalu ditambah $0,5 \mathrm{~mL}$ larutan jenuh $\mathrm{KI}$.
Larutan selanjutnya didiamkan selama 1 menit dengan kadangkala digoyang kemudian ditambah $30 \mathrm{~mL}$ aquadest. Campuran dititrasi dengan larutan baku natrium tiosulfat $0,1 \mathrm{~N}$ sampai warna kuning hampir hilang lalu ditambah $0,5 \mathrm{~mL}$ larutan pati $1 \%$. Titrasi dilanjutkan sampai warna biru tepat hilang. Dilakukan juga titrasi blanko dengan cara yang sama (banyaknya volume larutan baku tiosulfat untuk titrasi blanko tidak lebih dari $0,1 \mathrm{~mL}$ ).

Bilangan Peroksida $=\frac{1000 \times \mathrm{N} \times(\mathrm{V} 0-\mathrm{V} 1)}{\mathrm{W}}$

Keterangan:

$\mathrm{N}$ : Normalitas larutan standar natrium tiosulfat $(\mathrm{N})$

$\mathrm{V}_{0}$ : Volume larutan natrium tiosulfat yang digunakan untuk titrasi sampel $(\mathrm{mL})$

$V_{1}$ : Volume larutan natrium tiosulfat yang digunakan untuk titrasi blanko $(\mathrm{mL})$

W : Bobot contoh (g)

2. Kadar Asam Lemak Bebas (SNI 7709:2012)

Timbang $10 \mathrm{~g}$ sampai dengan $50 \mathrm{~g}$ contoh (W) ke dalam erlenmeyer. Larutkan dengan $50 \mathrm{~mL}$ etanol hangat dan tambahkan 5 tetes larutan fenolftalein. Titrasi larutan tersebut dengan $\mathrm{KOH}$ 0,1 $\mathrm{N}$ sampai terbentuk warna merah muda (warna merah muda bertahan selama 30 detik). Catat volume larutan $\mathrm{KOH}$ yang digunakan.

$$
\mathrm{FFA}=\frac{256 \times \mathrm{V} \times \mathrm{N}}{\mathrm{W} \times 1000} \times 100 \%
$$


Keterangan :

FFA: Asam lemak bebas

$\mathrm{V}$ : Volume larutan $\mathrm{KOH}$ yang digunakan $(\mathrm{mL})$

$\mathrm{N}$ : Normalitas larutan $\mathrm{KOH}(\mathrm{N})$

$\mathrm{W}$ : Bobot sampel (gram)

\section{Analisis Data}

Data yang diperoleh berupa kadar asam lemak bebas dan bilangan peroksida minyak goreng yang akan dianalisis secara statistik. Hasil kadar asam lemak bebas dan bilangan peroksida akan dibandingkan dengan nilai Standar Nasional Indonesia (SNI) yang telah ditetapkan oleh Badan Standarisasi Nasional (2012).

\section{HASIL DAN PEMBAHASAN}

Penelitian ini dilakukan untuk mengetahui aktivator yang paling berpengaruh pada kadar asam lemak bebas dan bilangan peroksida dari minyak jelantah dengan karbon aktif ampas tahu sebagai adsorben. Ampas tahu mengandung selulosa dengan jumlah sekitar 50\% (Li et al., 2013). Selulosa kaya akan gugus hidroksil $(-\mathrm{OH})$ yang bersifat elektronegatif (basa) dan polar, sehingga dapat berinteraksi dengan gugus karboksilat $(-\mathrm{COOH})$ dari FFA (Free Fatty Acid) yang bersifat elektropositif (asam) dan polar (Rahayu dan Purnavita, 2014). Senyawa peroksida yang terdapat dalam minyak mengandung gugus yang bersifat polar sehingga mudah diserap oleh gugus hidroksil dari selulosa yang bersifat polar. (Rahayu dan Purnavita, 2014).
Sebelum dilakukan pembuatan karbon aktif, ampas tahu dikeringkan untuk menurunkan kadar air yang ada dalam ampas tahu agar daya simpannya lebih lama. Setelah proses pengeringan, ampas tahu dihaluskan untuk memperbesar luas permukaan. Ampas tahu kemudian dikarbonisasi menggunakan tanur pada suhu $500^{\circ} \mathrm{C}$, karena pada suhu $500^{\circ} \mathrm{C}$ terjadi proses pemurnian karbon. Proses karbonisasi bertujuan untuk menguraikan senyawa hidrokarbon seperti selulosa dan hemiselulosa agar menjadi karbon murni dan menghasilkan butiran yang mempunyai daya serap (Hartini et al.., 2014). Setelah itu karbon ampas tahu diayak untuk memperluas dan menyeragamkan ukuran partikel - partikel dari karbon aktif. Kabon ampas tahu kemudian diaktivasi dengan beberapa aktivator, yaitu $\mathrm{NaCl} 10 \%, \mathrm{Na}_{2} \mathrm{CO}_{3} 5 \%$ dan $\mathrm{H}_{3} \mathrm{PO}_{4}$ 1M. Aktivasi dilakukan untuk memperbesar pori yaitu dengan cara memecahkan ikatan hidrokarbon atau mengoksidasi molekul-molekul permukaan sehingga arang mengalami perubahan sifat, baik fisika maupun kimia, yaitu luas permukaannya bertambah besar dan berpengaruh terhadap daya adsorpsi (Jamilatun dan Setyawan, 2014).

Pemurnian dengan menggunakan adsorben karbon aktif ampas tahu dilakukan untuk meningkatkan kembali mutu minyak goreng dengan tahapan proses despicing, netralisasi, dan bleaching. Minyak yang digunakan yaitu 
minyak goreng kemasan yang terlebih dahulu dianalisis kadar asam lemak bebas dan bilangan peroksida sebagai kontrol. Bahan pangan yang digoreng yaitu ikan basah, ikan kering, daging ayam dan tahu-tempe. Pada setiap penggorengan dilakukan analisis kadar asam lemak bebas dan bilangan peroksida sebagai parameter untuk menguji kualitas minyak.

Jumlah asam lemak bebas yang terdapat dalam minyak dapat menunjukkan kualitas minyak, semakin tinggi nilai asam lemak bebas, maka semakin turun kualitas. Kadar rata - rata asam lemak bebas pada minyak sebelum penggorengan yaitu $0,1369 \%, 0,1340 \%$ dan 0,1279\%, kadar tersebut masih dibawah kadar yang disyaratkan oleh SNI, yaitu $0,3 \%$. Kadar asam lemak bebas pada minyak semakin meningkat pada setiap pengulangan penggorengan. kandungan asam lemak bebas meningkat karena adanya proses hidrolisis. Reaksi hidrolisis disebabkan oleh kandungan air dalam bahan pangan yang digoreng (Gunawan et al.., 2003). Konsumsi asam lemak bebas yang cukup tinggi akan berakibat pada kenaikan kadar LDL dan menurunkan kadar HDL darah, mengurangi kemampuan tubuh mengendalikan gula darah karena dapat mengurangi respons terhadap hormon insulin. Konsumsi asam lemak yang tinggi dapat menaikkan resiko penyakit jantung (Sukmawati, 2014).

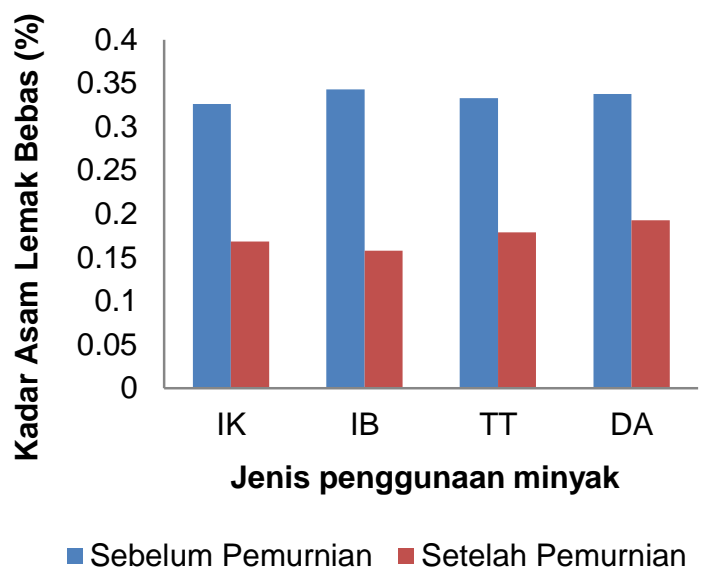

Gambar 1 Rata - Rata Penurunan Kadar Asam Lemak Bebas Pada Minyak Setelah Dimurnikan dengan karbon aktif ampas tahu yang diaktivasi dengan $\mathrm{NaCl}$

Minyak bekas penggorengan ikan basah, tahu-tempe dan daging ayam mengalami kerusakan pada penggorengan ke-7 dan ikan kering mengalami kerusakan pada penggorengan ke-6. Pada Gambar 1. terlihat bahwa karbon aktif ampas tahu yang diaktivasi dengan $\mathrm{NaCl}$ dapat menurunkan kadar asam lemak bebas pada minyak bekas penggorengan ikan kering yang sebelumnya $0,3263 \%$ menjadi 0,1684\%; ikan basah $0,3427 \%$ menjadi 0,1578\%; tahu-tempe 0,3327\% menjadi $0,1789 \%$ dan daging ayam 0,3375\% menjadi 0,1925\%. Kadar asam lemak bebas pada minyak bekas penggorengan ikan kering setelah dimurnikan dengan karbon aktif ampas tahu yang diaktivasi dengan $\mathrm{Na}_{2} \mathrm{CO}_{3}$ (Gambar 2) mengalami penurunan dari $0,3322 \%$ menjadi $0,1587 \%$; ikan basah $0,3481 \%$ menjadi 0,1473\%; tahu-tempe $0,3306 \%$ menjadi $0,1682 \%$ dan daging ayam 0,3323\% 
menjadi 0,1579\%. Minyak bekas penggorengan ikan kering setelah dimurnikan dengan karbon aktif ampas tahu yang diaktivasi dengan $\mathrm{H}_{3} \mathrm{PO}_{4}$ (Gambar 3.) kadar asam lemak bebasnya mengalami penurunan dari $0,3317 \%$ menjadi $0,1786 \%$; ikan basah $0,3523 \%$ menjadi $0,1840 \%$; tahu-tempe $0,3417 \%$ menjadi $0,1838 \%$ dan daging ayam $0,3297 \%$ menjadi $0,1784 \%$.

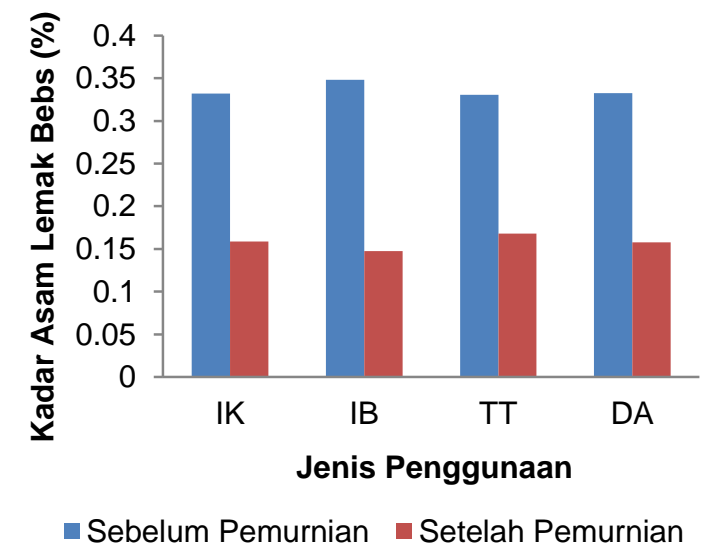

Gambar 2 Rata - Rata Penurunan Kadar Asam Lemak Bebas Pada Minyak Setelah Dimurnikan dengan karbon aktif ampas tahu yang diaktivasi dengan $\mathrm{Na}_{2} \mathrm{CO}_{3}$

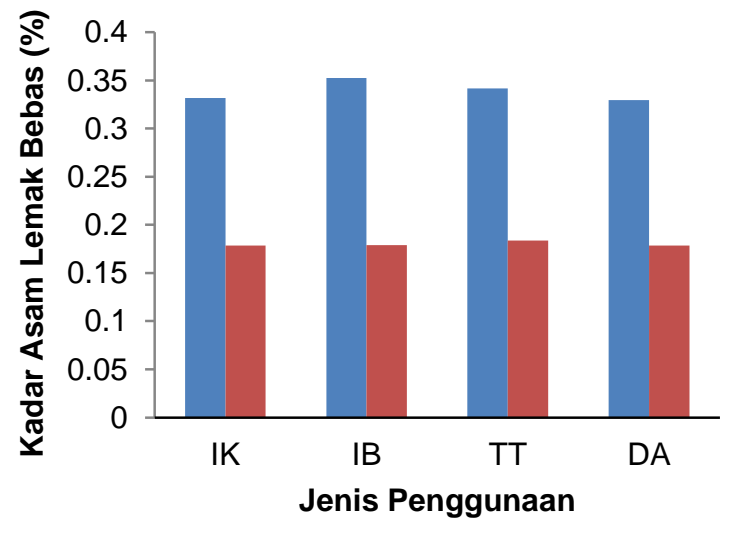

- Sebelum Pemurnian -Setelah Pemurnian

Gambar 3 Rata - Rata Penurunan Kadar Asam Lemak Bebas Pada Minyak Setelah Dimurnikan dengan karbon aktif ampas tahu yang diaktivasi dengan $\mathrm{H}_{3} \mathrm{PO}_{4}$
Bilangan peroksida adalah nilai terpenting untuk menentukan derajat kerusakan minyak. Bilangan peroksida menunjukkan tingkat kerusakan minyak karena oksidasi. Apabila minyak dipanaskan dan terkena udara maka akan mengalami reaksi-reaksi oksidasi. Kadar rata - rata bilangan peroksida pada minyak sebelum penggorengan yaitu 3,0154 meq $\mathrm{O}_{2} / \mathrm{kg}, 3,0113$ meq $\mathrm{O}_{2} / \mathrm{kg}$ dan 2,9964 meq $\mathrm{O}_{2} / \mathrm{kg}$, kadar tersebut masih dibawah kadar yang disyaratkan oleh SNI, yaitu $10 \mathrm{meq} \mathrm{O}_{2} / \mathrm{kg}$.

Bilangan peroksida pada minyak juga mengalami peningkatan pada tiap pengulangan penggorengan. Bilangan peroksida pada minyak meningkat karena terjadi reaksi dengan oksigen pada ikatan rangkap dan terjadi reaksi berantai terus menerus menyediakan radikal bebas yang menghasilkan ikatan peroksida lebih lanjut. Dengan adanya pemanasan asam lemak tidak jenuh terurai akibat permukaan minyak yang panas dan kontak langsung dengan udara. Rantai karbon yang terputus berikatan dengan oksigen sehingga peroksida minyak bertambah (Gunawan et al., 2003). Peroksida akan membentuk persenyawaan lipoperoksida. Lipoperoksida dalam aliran darah mengakibatkan denaturasi lipoprotein sehingga terjadi deposisi lemak dalam pembuluh darah (aorta) yang menimbulkan gejala atherosclerosis (Ketaren, 2008). 
Minyak bekas penggorengan lkan kering, tahu-tempe dan daging ayam mengalami kerusakan pada penggorengan ke- 6 dan ikan basah mengalami kerusakan pada penggorengan ke-7. Karbon aktif ampas tahu yang diaktivasi dengan $\mathrm{NaCl}$ dapat menurunkan bilangan peroksida (Gambar 4.) pada minyak bekas penggorengan ikan kering yang sebelumnya 10,5614 meq $\mathrm{O}_{2} / \mathrm{kg}$ menjadi 6,3394 meq $\mathrm{O}_{2} / \mathrm{kg}$; ikan basah 11,0308 meq $\mathrm{O}_{2} / \mathrm{kg}$ menjadi 5,7911 meq $\mathrm{O}_{2} / \mathrm{kg}$; tahu-tempe 13,1859 meq $\mathrm{O}_{2} / \mathrm{kg}$ menjadi 9,3202 meq $\mathrm{O}_{2} / \mathrm{kg}$ dan daging ayam 11,8874 meq $\mathrm{O}_{2} / \mathrm{kg}$ menjadi 8,4614 meq $\mathrm{O}_{2} / \mathrm{kg}$.

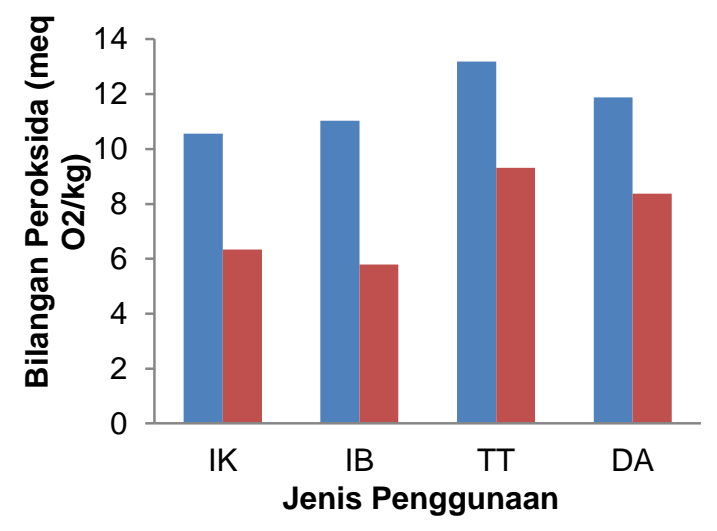

- Sebelum Pemurnian — Setelah Pemurnian

Gambar 4 Rata - Rata Penurunan Bilangan Peroksida Pada Minyak Setelah Dimurnikan dengan karbon aktif ampas tahu yang diaktivasi dengan $\mathrm{NaCl}$

Bilangan peroksida pada minyak bekas penggorengan ikan kering setelah dimurnikan dengan karbon aktif ampas tahu yang diaktivasi dengan $\mathrm{Na}_{2} \mathrm{CO}_{3}$ (Gambar 5.) mengalami penurunan dari 10,6288 meq $\mathrm{O}_{2} / \mathrm{kg}$ menjadi 4,3526 meq $\mathrm{O}_{2} / \mathrm{kg}$; ikan basah 10,7903 meq $\mathrm{O}_{2} / \mathrm{kg}$ menjadi $7,3737 \mathrm{meq} \mathrm{O}_{2} / \mathrm{kg}$; tahu-tempe
13,8164 meq $\mathrm{O}_{2} / \mathrm{kg}$ menjadi 6,9485 meq $\mathrm{O}_{2} / \mathrm{kg}$ dan daging ayam 11,6233 meq $\mathrm{O}_{2} / \mathrm{kg}$ menjadi 5,1527 meq $\mathrm{O}_{2} / \mathrm{kg}$.

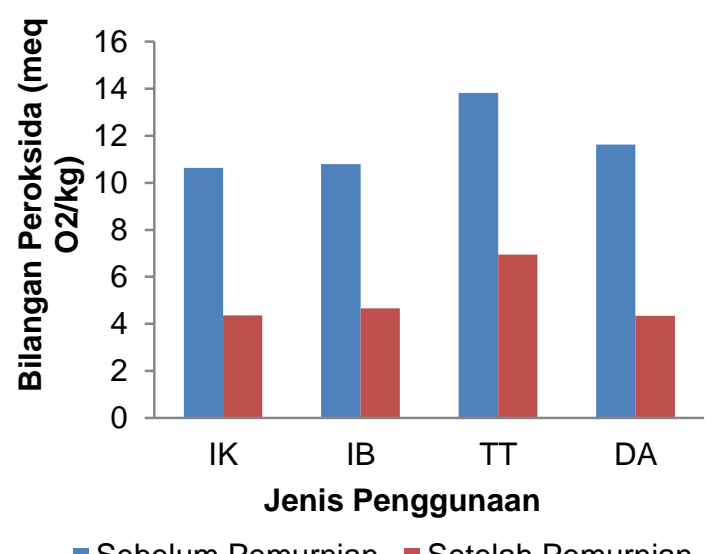

- Sebelum Pemurnian - Setelah Pemurnian

Gambar 5 Rata - Rata Penurunan Bilangan Peroksida Pada Minyak Setelah Dimurnikan dengan karbon aktif ampas tahu yang diaktivasi dengan $\mathrm{Na}_{2} \mathrm{CO}_{3}$

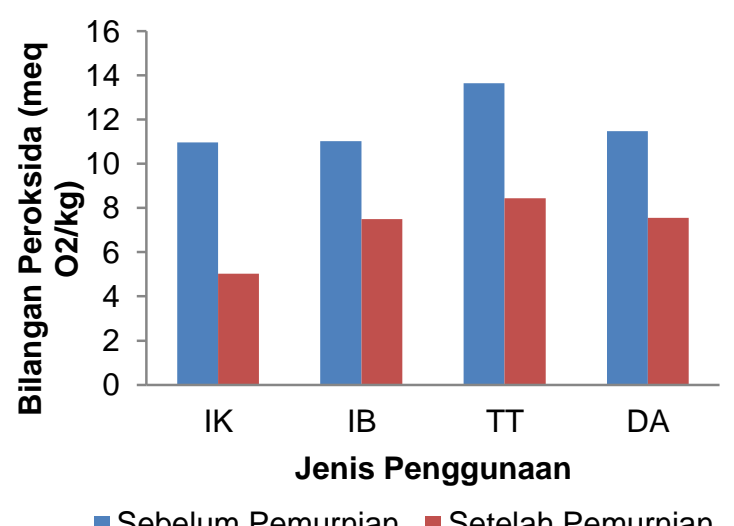

Gambar 6 Rata - Rata Penurunan Bilangan Peroksida Pada Minyak Setelah Dimurnikan dengan karbon aktif ampas tahu yang diaktivasi dengan $\mathrm{H}_{3} \mathrm{PO}_{4}$

Minyak bekas penggorengan ikan kering setelah dimurnikan dengan karbon aktif ampas tahu yang diaktivasi dengan $\mathrm{H}_{3} \mathrm{PO}_{4}$ (Gambar 6) bilangan peroksidanya mengalami penurunan dari 10,9672 meq $\mathrm{O}_{2} / \mathrm{kg}$ menjadi 5,0333 meq $\mathrm{O}_{2} / \mathrm{kg}$; ikan basah 11,0265 meq $\mathrm{O}_{2} / \mathrm{kg}$ menjadi 7,5057 
meq $\mathrm{O}_{2} / \mathrm{kg}$; tahu-tempe 13,6568 meq $\mathrm{O}_{2} / \mathrm{kg}$ menjadi 8,4359 meq $\mathrm{O}_{2} / \mathrm{kg}$ dan daging ayam 11,4803 meq $\mathrm{O}_{2} / \mathrm{kg}$ menjadi $7,5918 \mathrm{meq} \mathrm{O}_{2} / \mathrm{kg}$.

Berdasarkan hasil statistik one way ANOVA, menunjukkan bahwa terdapat perbedaan yang signifikan antara kadar asam lemak bebas pada daging ayam $(p=0.017)$ dan ikan basah $(p=0.038)$ diantara ke tiga jenis aktivator dengan nilai $p<0.05$ dan terdapat perbedaan yang signifikan kadar bilangan peroksida pada ayam $(p=0.000)$, ikan basah $(p=0.000)$, ikan kering $(p=0.001)$ dan tahu-tempe $(p=0.000)$ diantara ke tiga jenis aktivator dengan nilai $p<0.05$. Setelah itu dilakukan uji lanjut LSD (Least Significance Different), untuk mengetahui ada tidaknya perbedaan antar kelompok perlakuan. Uji lanjut dengan uji LSD pada kadar asam lemak bebas terdapat perbedaan yang signifikan kadar asam lemak bebas pada daging ayam antara jenis adsorben $\mathrm{NaCl}$ dengan $\mathrm{Na}_{2} \mathrm{CO}_{3}(p=0.006)$ dan $\mathrm{Na}_{2} \mathrm{CO}_{3}$ dengan $\mathrm{H}_{3} \mathrm{PO}_{4}$ juga terdapat perbedaan yang signifikan dengan nilai $p=0.050$. Adapun kadar asam lemak bebas pada ikan basah yaitu ditemukan perbedaan yang signifikan pada adsorben $\mathrm{Na}_{2} \mathrm{CO}_{3}$ dengan $\mathrm{H}_{3} \mathrm{PO}_{4}(\mathrm{p}=0.01)$. Hasil uji lanjut bilangan peroksida pada daging ayam menunjukkan adanya perbedaan signifikan antara jenis adsorben $\mathrm{NaCl}$ dengan $\mathrm{Na}_{2} \mathrm{CO}_{3}(p=0.00), \mathrm{NaCl}$ dengan $\mathrm{H}_{3} \mathrm{PO}_{4} \quad(p=0.02)$ dan $\mathrm{Na}_{2} \mathrm{CO}_{3}$ dengan $\mathrm{H}_{3} \mathrm{PO}_{4}(p=0.00)$. Bilangan peroksida pada ikan kering terdapat perbedaan yang signifikan antara jenis adsorben $\mathrm{NaCl}$ dengan $\mathrm{Na}_{2} \mathrm{CO}_{3}(p=0.00), \mathrm{NaCl}$ dengan $\mathrm{H}_{3} \mathrm{PO}_{4} \quad(p=0.00)$ dan $\mathrm{Na}_{2} \mathrm{CO}_{3}$ dengan $\mathrm{H}_{3} \mathrm{PO}_{4}(p=0.04)$. Bilangan peroksida pada ikan basah terdapat perbedaan yang signifikan antara jenis adsorben $\mathrm{NaCl}$ dengan $\mathrm{Na}_{2} \mathrm{CO}_{3}(p=0.01), \mathrm{NaCl}$ dengan $\mathrm{H}_{3} \mathrm{PO}_{4} \quad(p=0.00)$ dan $\mathrm{Na}_{2} \mathrm{CO}_{3}$ dengan $\mathrm{H}_{3} \mathrm{PO}_{4} \quad(p=0.00)$. Adapun bilangan peroksida pada tahu-tempe yaitu ditemukan perbedaan yang signifikan antara jenis adsorben $\mathrm{NaCl}$ dengan $\mathrm{Na}_{2} \mathrm{CO}_{3} \quad(p=0.00), \quad \mathrm{NaCl}$ dengan $\mathrm{H}_{3} \mathrm{PO}_{4}$ $(p=0.01)$ dan $\mathrm{Na}_{2} \mathrm{CO}_{3}$ dengan $\mathrm{H}_{3} \mathrm{PO}_{4}$ $(p=0.00)$.

\section{KESIMPULAN}

Aktivator yang paling berpengaruh pada penurunan kadar asam lemak bebas dan bilangan peroksida adalah $\mathrm{Na}_{2} \mathrm{CO}_{3}$ dimana diperoleh kadar rata - rata asam lemak bebas $0,1473 \%$ dengan persentase penurunan sebesar $57,68 \%$. Kadar rata rata penurunan bilangan peroksida yaitu 4,3526 meq $\mathrm{O}_{2} / \mathrm{kg}$ dengan persentase penurunan sebesar $59,04 \%$.

\section{DAFTAR PUSTAKA}

Badan Standarisasi Nasional. (2012). Syarat Mutu Minyak Goreng Kelapa Sawit. SNI, 7709, 2012.

Barau, F. (2014). Buah Mengkudu (Morinda citrifolia L.) sebagai Pengadsorbsi Minyak Jelantah. Skripsi. Palu: Fakultas Keguruan dan IImu Pendidikan Universitas Tadulako.

Fadlia. (2016). Analisis Mutu Minyak Jelantah dengan Netralisasi Adsorben Biji Salak (Salacca zalacca (Gaertn.) Voss) 
Menggunakan Parameter Bilangan Peroksida dan Asam Lemak Bebas. Skripsi. Palu: Fakultas Matematika dan IImu Pengetahuan Alam Universitas Tadulako.

Gunawan, Triatmo, M, Rahayu, A. (2003). Analisis Pangan: Penentuan Angka Peroksida dan Asam Lemak Bebas Pada Minyak Kedelai Dengan Variasi Menggoreng. JSKA. 6(3).

Hartini, L, Yulianti, E, Mahmudah, R. (2014). Karakterisasi Karbon Aktif Teraktivasi $\mathrm{NaCl}$ dari Ampas Tahu. ALCHEMY. 3(2):145-153

Jamilatun, S, Setyawan, M. (2014). Pembuatan Arang Aktif dari Tempurung Kelapa dan Aplikasinya untuk Penjernihan Asap Cair. Spektrum Industri. 12(1):73-86

Ketaren, S. (2008). Minyak dan Lemak Pangan. Jakarta: UI-Press.

Nasir, NSW. (2014). Pemanfaatan Arang Aktif Kulit Pisang Kepok (Musa normalis) sebagai Adsorben untuk Menurunkan Angka Peroksida dan Asam Lemak Bebas Minyak Goreng Bekas. Skripsi. Palu: Fakultas Matematika dan IImu Pengetahuan Alam Universitas Tadulako.

Rahayu, LH., Purnavita, S. (2014). Pengaruh Suhu dan Waktu Adsorpsi Terhadap Sifat Kimia-Fisika Minyak Goreng Bekas Hasil Pemurnian Menggunakan Adsorben Ampas Pati Aren dan Bentonit. Momentum. 10(2):35-41

Rohman, A., Sumantri. (2007). Analisis Makanan. Yogyakarta: Gadjah Mada University Press.

Shimofuruya, H., Shimono, A., Kunieda, Y. (2011). Adsorption of Methyl Orange by Okara. J. Technology and Education. 18(1):5-8

Sukmawati, M. C. (2014). Analisis Kandungan Kolesterol, Asam Lemak Bebas dan Angka Peroksida Pada Makanan
Tradisional Khas Makassar (Coto, Konro dan Pallubasa). Media Gizi Pangan. 17(1):1-6

Wiyaningsih, F. (2010). Pengaruh Variasi Suhu Pemanasan Karbon Aktif Polong Buah Kelor (Moringa oleifera Lamk.) Terhadap Perubahan Angka Peroksida dan Asam Lemak Bebas (FFA) pada Proses Bleaching Minyak Goreng Bekas. Skripsi. Malang: Fakultas Sains dan Teknologi Universitas Islam Negeri (UIN) Maulana Malik Ibrahim. 